\title{
Gross morphology and topographical relationships of the hyobranchial apparatus and laryngeal cartilages in the ostrich (Struthio camelus)
}

\author{
John T. Soley ${ }^{1}$, Catarina Tivane $e^{1,2}$ and Martina R. Crole ${ }^{1, *}$ \\ ${ }^{1}$ Department of Anatomy and Physiology, Faculty of Veterinary Science, University of Pretoria, Onderstepoort, \\ South Africa \\ ${ }^{2}$ Preclinical Department, Veterinary Faculty, Eduardo Mondlane University, PO Box 257, Maputo, \\ Mozambique
}

*Martina R. Crole, Department of Anatomy and Physiology, Faculty of Veterinary Science, University of Pretoria, Private Bag X04, Onderstepoort 0110, South Africa. E-mail: martina.crole@ up.ac.za

\begin{abstract}
The ostrich hyobranchial apparatus consists of the centrally positioned paraglossalia and basiurohyale and paired caudo-lateral elements (horns), each consisting of the ceratobranchiale and epibranchiale. The paraglossalia lie within the tongue parenchyma and consist of paired, flat, caudo-laterally directed cartilages joined rostrally. The basiurohyale forms a single dorso-ventrally flattened unit composed of an octagonal-shaped body from which extend rostral (the rostral process) and caudal (the urohyale) projections. The laryngeal skeleton consists of cricoid, procricoid and paired arytenoid cartilages. The large ring-shaped cricoid cartilage displays a body and paired wings which articulate with each other and with the procricoid. The blunt, ossified, rostral projection of the cricoid and the scalloped nature of the arytenoid cartilages are unique to the ostrich. The procricoid is a single structure which links the paired arytenoids and wings of the cricoid. The hyobranchial apparatus is firmly attached to the tongue parenchyma and to the larynx and proximal trachea. In contrast to previous reports in this species, the horns of the hyobranchial apparatus are not related to the skull. Ossification of the body of the basihyale, the ceratobranchials and the rostral process and body of the cricoid cartilage of the larynx lends stability to these structures.
\end{abstract}

\section{Introduction}

In a comprehensive study of the lingual apparatus of the domestic chicken, Homberger and Meyers (1989) note that in birds, the lingual apparatus 'cooperates with the jaw apparatus and the larynx in generating carefully coordinated movements during various behaviours, such as feeding and drinking'. As an important component of the lingual apparatus, the hyobranchial apparatus, by virtue of its role in providing an attachment for lingual muscles and fasciae and anchoring certain salivary glands (Homberger and Meyers 1989), forms an essential structural element of the upper digestive tract. Likewise, the larynx which constitutes a considerable part of the floor of the oropharynx is reported to play 'an important part in several functions, including respiration and feeding' (McLelland 1989).

The hyobranchial apparatus of birds has been described in a number of species, particularly in galliform birds [see review by Homberger and Meyers (1989)] and its structure has been clearly defined. The various components of the apparatus originate principally from elements 
of the hyoid arch and the more caudally positioned branchial (pharyngeal) arches (Baumel and Witmer 1993). Although species-based structural variations occur, and taking differences in anatomical nomenclature into account, the basic components of the avian hyobranchial apparatus are the paraglossum, basihyale, urohyale and cornu branchiale composed of the ceratobranchiale and epibranchiale (King and McLelland 1984; Homberger and Meyers 1989; Baumel and Witmer 1993).

Although the hyobranchial apparatus or selected elements thereof have been noted or briefly described in ratite species such as the kiwi (Apteryx australis, Apteryx oweni, Apteryx haastii and Apteryx bulleri) (Owen 1879; Parker 1891), cassowary (Casuarius bennettii) (Parker 1866), greater rhea (Rhea americana) (Parker 1866; Feder 1972; Bonga Tomlinson 2000; Crole and Soley 2012a) and emu (Parker 1866; Bonga Tomlinson 2000; Crole and Soley 2009a, 2010, 2012b), no comprehensive account of its structure or topographical relationships has been presented. The structure of the hyobranchial apparatus of the ostrich has received wider attention (Warren 1725; Parker 1866; Duerden 1912; Webb 1957; Bezuidenhout 1999; Bonga Tomlinson 2000; Porcescu 2007; Jackowiak and Ludwig 2008; Tadjalli et al. 2008; Guimarães et al. 2009; Crole and Soley 2012b), and although some of these studies offer a more complete and accurate description (Webb 1957; Bonga Tomlinson 2000; Crole and Soley 2012b), they fail to relate the full anatomical details and topographical relationships of this structure in its entirety. The situation is further complicated in this species by the perpetuation in the literature of certain inaccuracies, particularly in respect of the structure of the paraglossalia.

The structure of the avian larynx has also been reported in a number of studies (see review by McLelland 1989), and the laryngeal cartilages have been described in a variety of species (Boccius 1858; White 1975; Bock 1978; Zweers et al. 1981; Hogg 1982; McLelland 1989). From these studies, it was concluded that birds have four laryngeal cartilages, namely the cricoid, procricoid and paired arytenoid cartilages. In ratites, accounts have been presented of the laryngeal cartilages in the emu (McLelland 1989 sketch by S.S. White; Bonga Tomlinson 2000; Crole and Soley 2012b), greater rhea (Bonga Tomlinson 2000; Crole and Soley 2012a) and ostrich (McLelland 1989; Bezuidenhout 1999; Bonga Tomlinson 2000; Porcescu 2007; Tadjalli et al. 2008; Poost Pasand et al. 2010a; Crole and Soley 2012b). The most comprehensive of the above studies was that of the greater rhea (Crole and Soley 2012a) in which the four laryngeal cartilages typically found in birds were identified. However, none of the previous reports on the ostrich provide a complete and/or accurate description of the laryngeal cartilages in this species.

In ratites, the important role of those elements of the hyobranchial apparatus related to the lingual apparatus has recently been highlighted, revealing species-specific structural/functional specialisations in the greater rhea (Crole and Soley 2012a) and in the ostrich and emu (Crole and Soley 2012b). Similarly, the larynx has been demonstrated to form an integral component of a newly described mechanism in ratites, the linguo-laryngeal apparatus which functions to protect the glottis during swallowing (Crole and Soley 2012b). Despite the relatively large number of publications on the hyobranchial apparatus and laryngeal cartilages of the ostrich, the lack of a comprehensive anatomical description coupled with the perpetuation of incorrect information and the use of variable terminology in naming anatomical structures, makes it imperative to accurately describe these important supportive components of the upper digestive tract. This paper therefore presents a 
comprehensively illustrated, detailed and definitive description of the gross morphology and topographical relationships of the hyobranchial apparatus and laryngeal cartilages in the ostrich. The terminology used is that of Nomina Anatomica Avium (Baumel et al. 1993).

\section{Materials and Methods}

The heads of nine subadult (12- to 14-month-old) ostriches were obtained from a commercial abattoir (Oryx Abattoir, Krugersdorp, Gauteng Province, South Africa) in 2005 immediately after the birds had been slaughtered. The heads were rinsed in running tap water to remove traces of mucus, blood and regurgitated food, immersion-fixed in 10\% neutral-buffered formalin and transported to the Faculty of Veterinary Science, University of Pretoria, where they remained in fixative for at least $48 \mathrm{~h}$. The fixed specimens were rinsed in running water for 2 days after which they were carefully dissected as follows to expose the relevant anatomical features. The skin and subcutaneous tissue were removed from the ventral aspect of the mandible and adjacent neck region of three heads to expose the in situ positioning of the hyoid apparatus and its relationship to the larynx (Figs 1 and 2). The hyobranchial

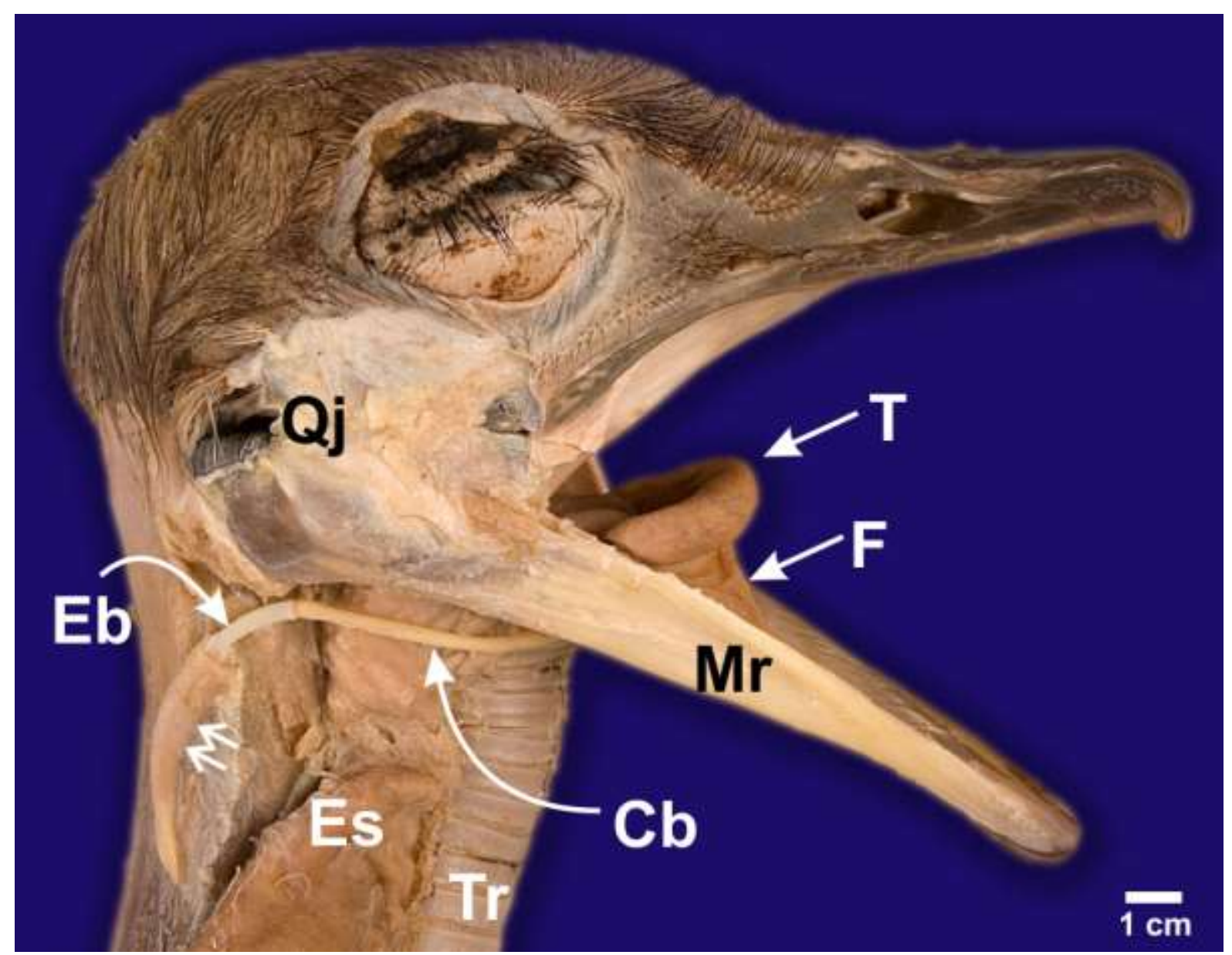

Figure 1. Right lateral view of the head and proximal neck region of a subadult ostrich dissected to reveal the in situ positioning of the hyobranchial apparatus. The right horn of the apparatus is represented by the ceratobranchiale $(\mathrm{Cb})$ and epibranchiale $(\mathrm{Eb})$. The Fascia vaginalis that houses the horn has been removed except for that portion covering the distal part of the epibranchiale (double arrows). Tongue body (T), frenulum (F), trachea (Tr), oesophagus (Es), mandibular ramus (Mr) and quadrato-mandibular joint (Qj). 

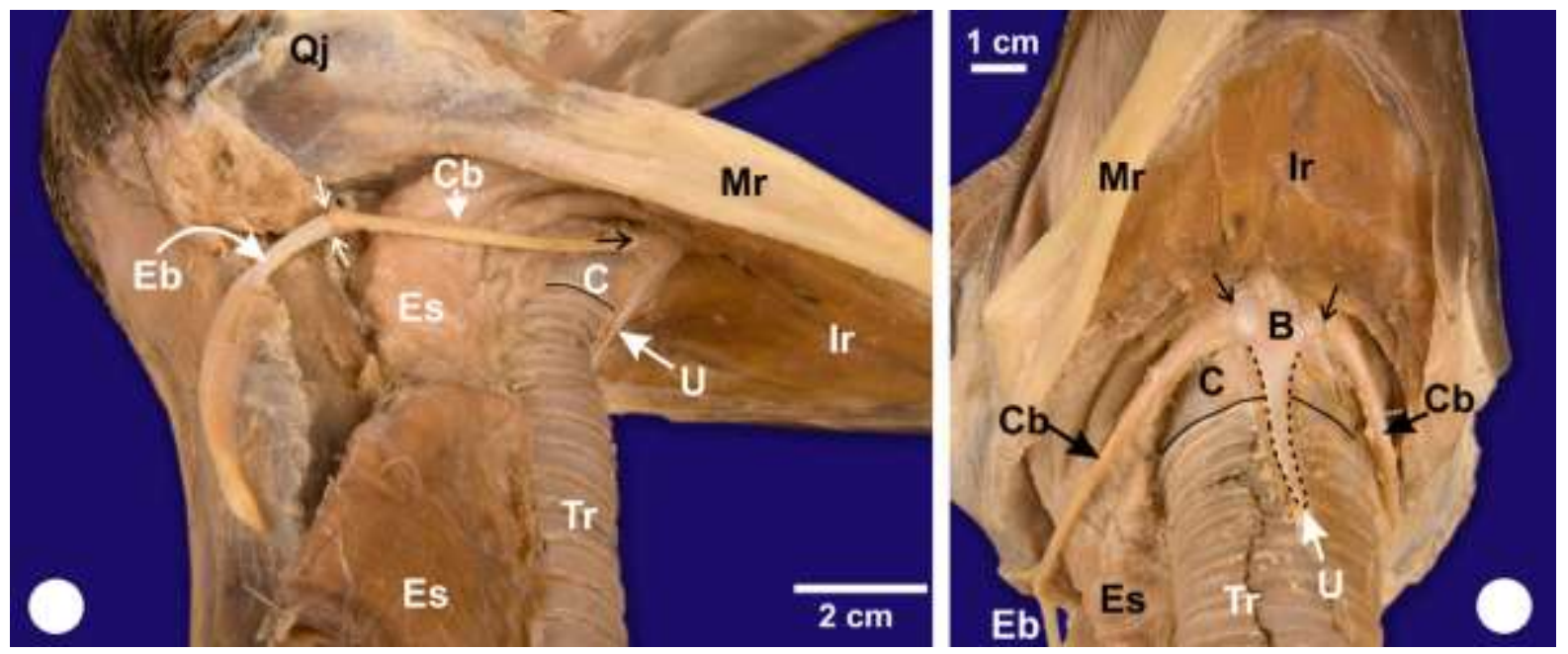

Figure 2. Right ventro-lateral view ( - A.) and ventral view $(-$ B.) of the head illustrated in Fig. 1. - A. The connection of the ceratobranchiale $(\mathrm{Cb})$ to the body of the basihyale is indicated (black arrow). Note the colour difference between the ossified ceratobranchiale and the cartilaginous epibranchiale $(\mathrm{Eb})$ and the articulation (white arrows) between the two components. Quadrato-mandibular joint (Qj), mandibular ramus (Mr), interramal region (Ir), cricoid cartilage (C) (the base of the cartilage has been outlined for clarity), trachea (Tr), urohyale (U) and oesophagus (Es). - B. The connection (small black arrows) of both the left and right ceratobranchiale $(\mathrm{Cb})$ to the body of the basihyale $(\mathrm{B})$ is demonstrated. The urohyale (U) (outlined for clarity) is firmly attached to the body of the cricoid cartilage (C) (base outlined for clarity) of the larynx and to the first number of tracheal rings. Trachea (Tr), mandibular ramus (Mr), inter-ramal region (Ir), epibranchiale (Eb) and oesophagus (Es).

apparatus, together with the tongue, larynx and trachea, was removed as a unit from the remaining six heads. Three of these specimens were air-dried to demonstrate the topographical relationship between the various components, while the remaining three were freed of all mucous membranes and connective tissue to expose the underlying cartilaginous/bony structures (Figs 3, 4 and 5). To confirm the findings in subadult birds and to determine any age-related changes, the heads of two 1-day-old ostrich chicks and two 3month-old birds killed as part of a nutritional trial (protocol number 36/5/0623, Faculty of Veterinary Science, University of Pretoria) were also examined. The morphology and topographical relationships of the hyoid apparatus and laryngeal cartilages were described and digitally recorded using a Nikon 4500 Coolpix 995 (Nikon, Tokyo, Japan) camera. This research was conducted at the Faculty of Veterinary Science (protocol number V023/06), University of Pretoria, South Africa, and was approved by the Research Committee and the Animal Use and Care Committee. 


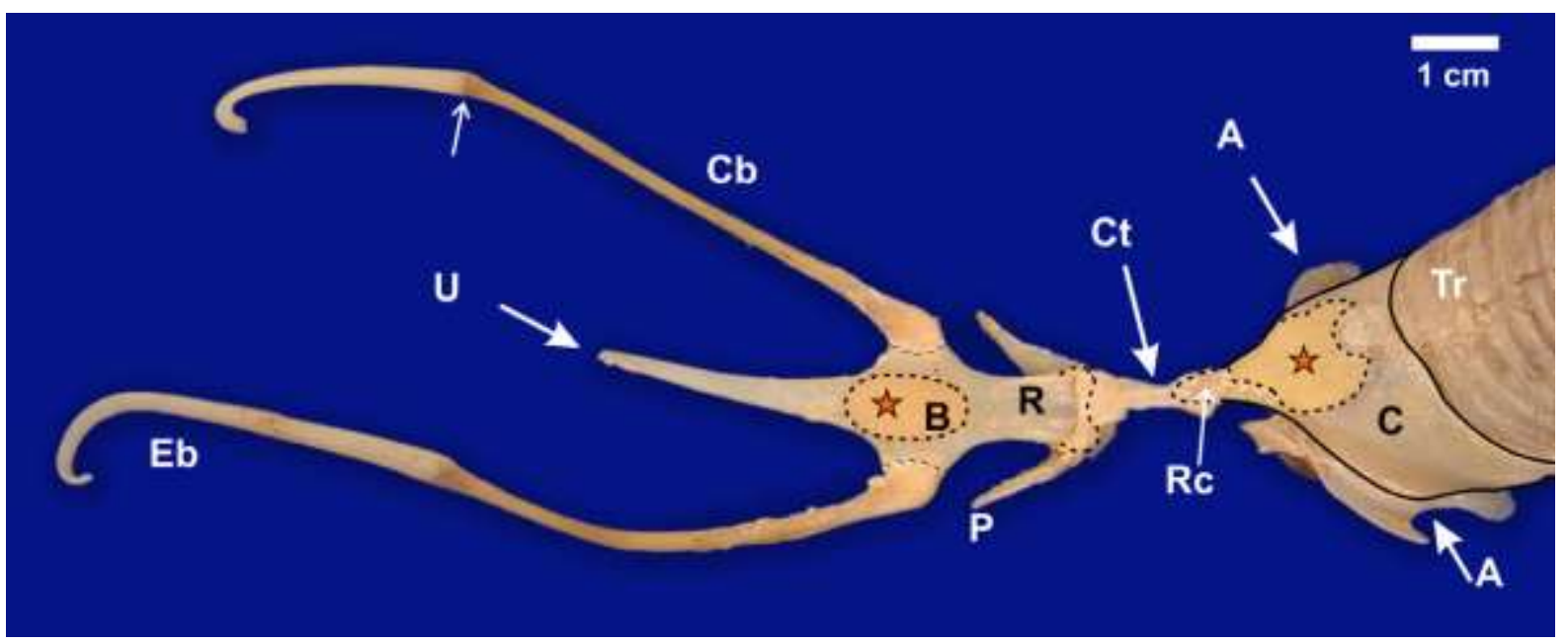

Figure 3. The hyobranchial apparatus reflected from the cricoid cartilage (C) and trachea (Tr) to reveal its dorsal surface. Note the paired paraglossals $(\mathrm{P})$, body of the basihyale $(\mathrm{B})$, the rostral projection of the basihyale $(\mathrm{R})$, the urohyale $(\mathrm{U})$, ceratobranchiale $(\mathrm{Cb})$ and epibranchiale $(\mathrm{Eb})$. A band of fibrous connective tissue $(\mathrm{Ct})$ attaches the rostral projection and body of the basihyale (from which it has been reflected) to the rostral projection (Rc) of the cricoid cartilage (outlined for clarity). The points of articulation between the ceratobranchiale and body of the basihyale (white dotted lines) and between the ceratobranchiale and epibranchiale (white arrow) are shown. The regions of ossification of the body of the basihyale (encircled and with star) and the body of the cricoid cartilage (encircled and with star) are clearly visible. Arytenoid cartilages (A). The distal tips of the epibranchiale are artificially curved in this dissected specimen.
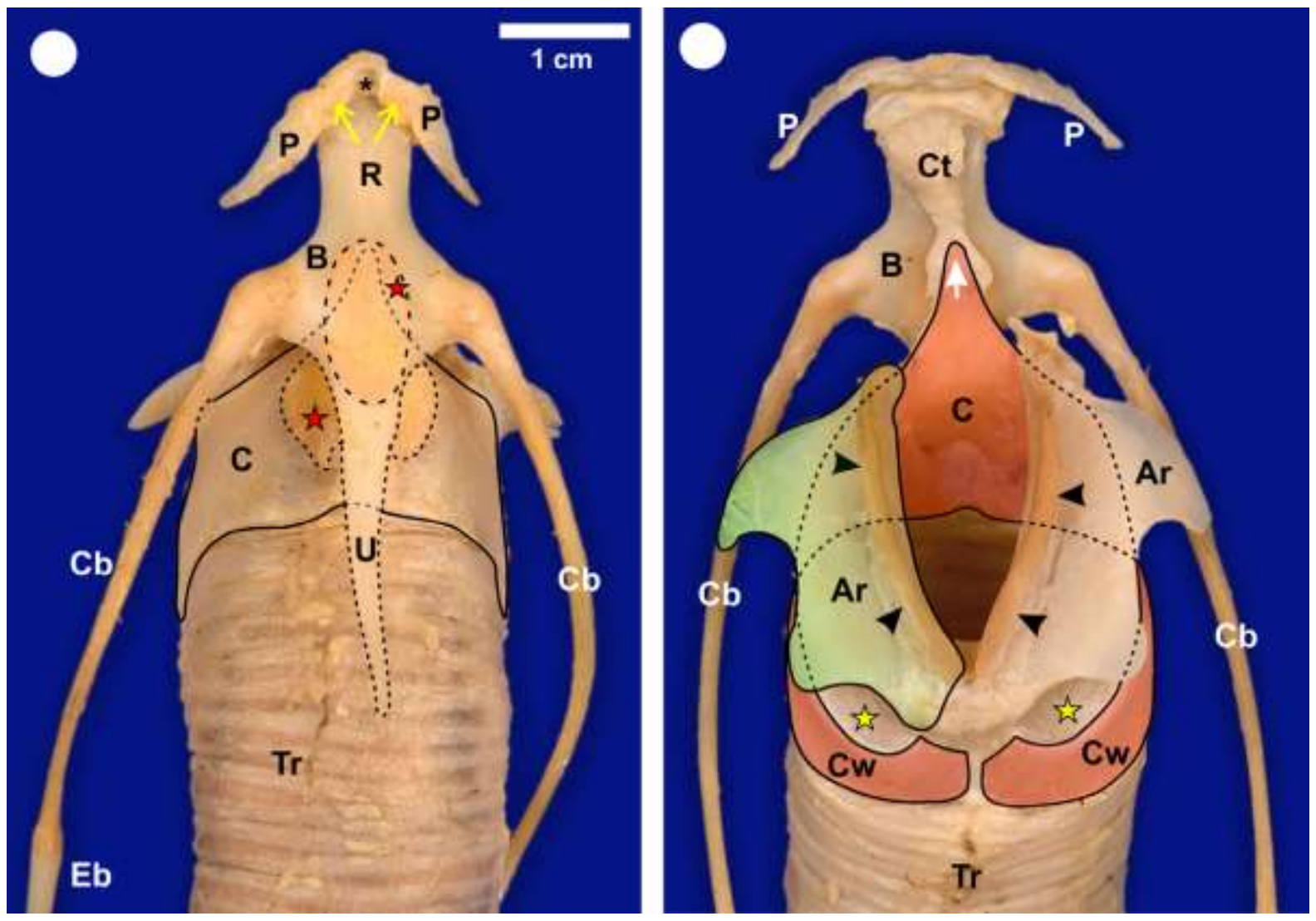

Figure 4. Enlarged ventral (-A.) and dorsal (-B.) view of the hyobranchial apparatus and laryngeal cartilages. - A. The paired paraglossals $(\mathrm{P})$ are attached to each other $\left(^{*}\right)$ and to the rostral process $(\mathrm{R})$ of the basihyale (yellow arrows) by fibrous connective tissue. Note the octagonal shape of the body (B) of the basihyale and the ossification of the body of both the basihyale (dotted outline on B with star) and cricoid (C) cartilage (dotted 
outline on $\mathrm{C}$ with star). The narrow tail of the urohyale (U) (outlined for clarity) extends along approximately six tracheal rings. Cricoid cartilage $(\mathrm{C})$ (outlined for clarity), ceratobranchiale $(\mathrm{Cb})$, epibranchiale $(\mathrm{Eb})$ and trachea $(\mathrm{Tr})$. - B. The fibrous attachment $(\mathrm{Ct})$ between the rostral process of the cricoid cartilage (white arrow) and the rostral process of the basihyale is obvious. The arytenoid cartilages (Ar) (left side outlined and shaded green for clarity) with their distinctive projections are shown. Note the mucosa-lined apertures (yellow stars) between the arytenoid cartilages and the wings of the cricoid cartilage $(\mathrm{Cw})$ (shaded red). The raised rim of the glottis (arrowheads) represents well-developed mucosal folds not removed during dissection of the larynx. Trachea (Tr), ceratobranchiale $(\mathrm{Cb})$, paired paraglossals $(\mathrm{P})$ and body of the basihyale $(\mathrm{B})$. The cricoid cartilage (C) is outlined and shaded red for greater clarity.

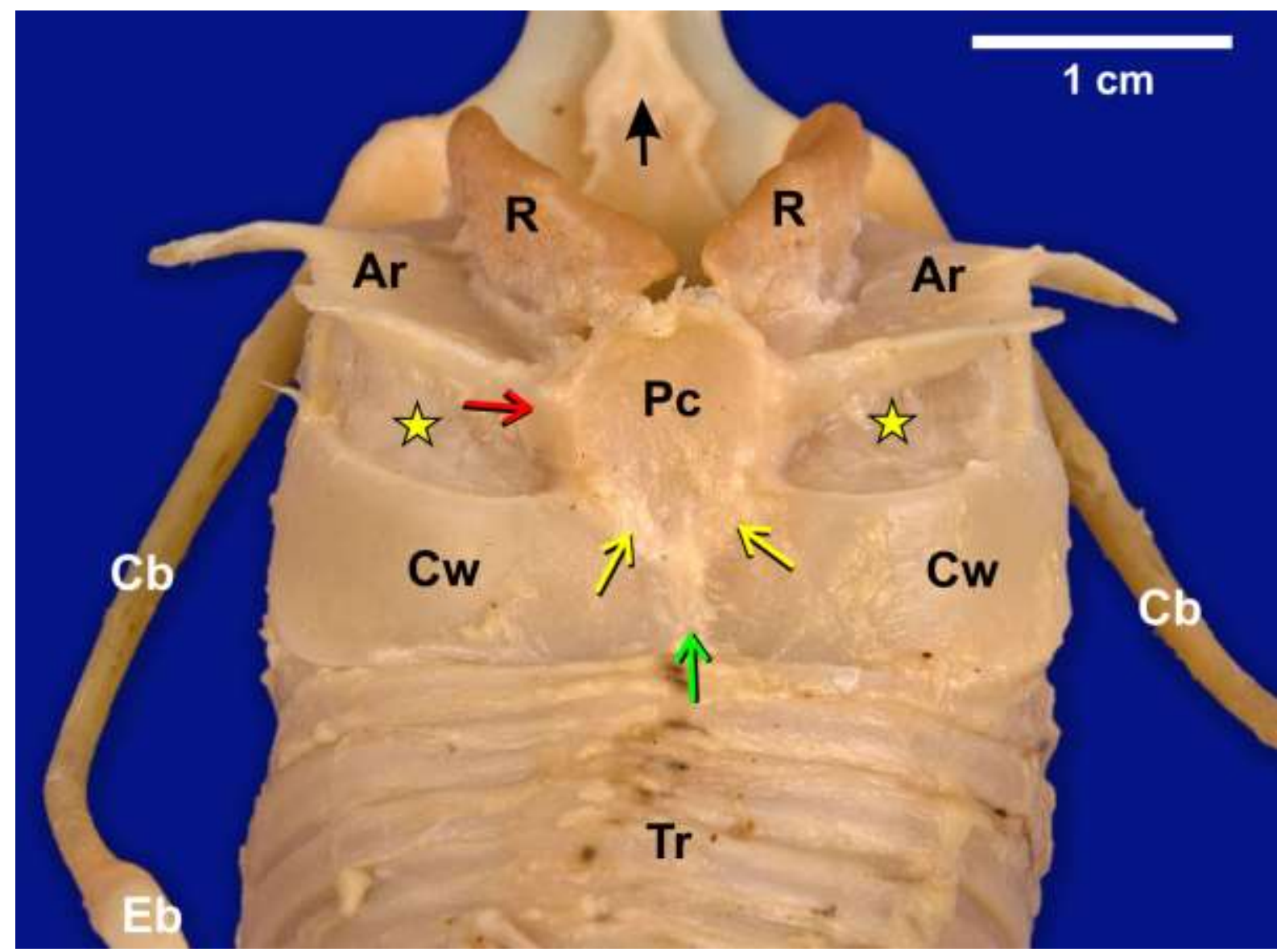

Figure 5. A caudo-dorsal view of the laryngeal skeleton illustrating the union of the procricoid cartilage (Pc) with the wings $(\mathrm{Cw})$ of the cricoid cartilage (yellow arrows) and the caudo-medial aspect (red arrow) of the two arytenoid cartilages (Ar). The wings of the cricoid cartilage also link with each other below the procricoid cartilage (green arrow). The elevated mucosal ridges $(\mathrm{R})$ or lips running along the rim of the glottis are obvious. Trachea (Tr), ceratobranchiale $(\mathrm{Cb})$, epibranchiale $(\mathrm{Eb})$, mucosa-lined apertures (yellow stars) and rostral projection of the cricoid cartilage (black arrow - see also Fig. 4B).

\section{Results}

\section{The hyobranchial apparatus (Apparatus hyobranchialis)}

The hyobranchial apparatus of the ostrich consisted of two centrally positioned elements (components) (paired paraglossals and a fused basihyale and urohyale) and paired caudolateral elements, the horns (соrnu) each consisting of the ceratobranchiale and epibranchiale (Figs 3 and 4). 
The paraglossals (paraglossalia) formed the most rostral component of the hyobranchial apparatus (Figs 3, 4 and 6). They comprised paired, relatively narrow, flat cartilages that were connected rostrally to each other and along the rostral third of their length to the tip of the rostral projection of the fused basihyale and urohyale, by a sheet of loosely arranged fibrous connective tissue (Fig. 4A). Each cartilage curved caudo-laterally to form the cartilaginous support of the ventro-lateral aspect of the tongue, was broader rostrally where they were attached to each other and tapered caudally to end in a pointed tip (Figs 3 and 4).

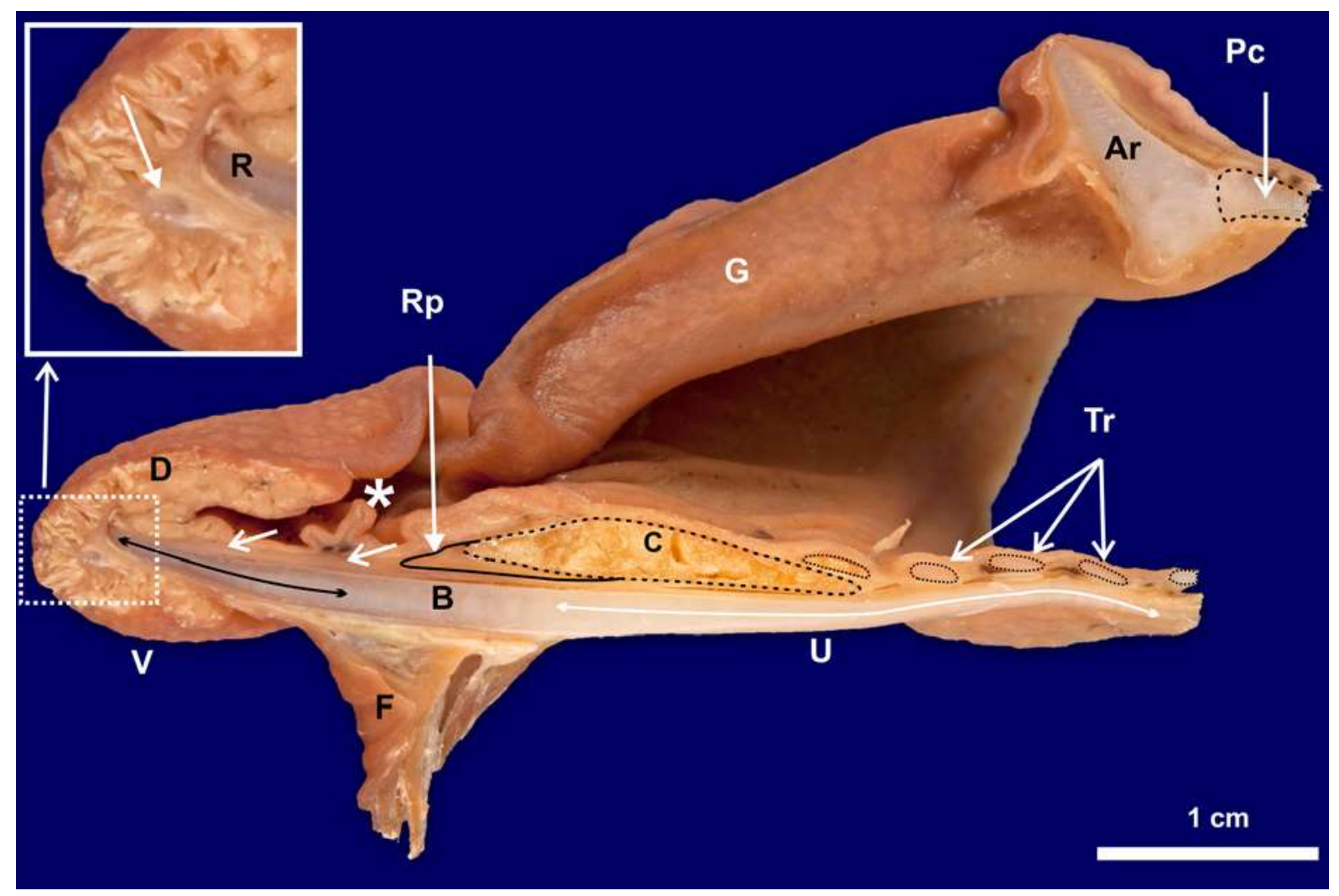

Figure 6. A mid-saggital section through the tongue and larynx showing the relationship between the basihyale (B) and the more dorsally positioned rostral process (Rp) of the cricoid (C), which in this specimen is ossified (dotted outline). Only a small portion of the paraglossalia (arrow on the inset) is visible on the photograph, ventral to the rostral projection $(\mathrm{R})$ of the basihyale. Note the band of dense connective tissue (white arrows) running between the rostral process of the basihyale (black double-headed arrow) and the rostral process of the cricoid cartilage. Dorsal surface (D) and ventral surface $(\mathrm{V})$ of the tongue body, tongue pocket $(*)$, frenulum $(\mathrm{F})$, tracheal rings (Tr, outlined), urohyale (white double-headed arrow, U), lips of the glottis $(\mathrm{G})$, arytenoid cartilage (Ar) and procricoid cartilage $(\mathrm{Pc}$, outlined).

The remaining central component, which represented the basihyale and urohyale described in birds (Baumel and Witmer 1993), consisted of a single, dorso-ventrally flattened, cartilaginous unit composed of an octagonal-shaped body (corpus) (Figs 3 and 4A) from which extended rostral and caudal projections (Figs 3, 4 and 6). In most of the 12- to 14month-old birds, the body was ossified (Figs 3 and 4A) but in some specimens from this group, and in 3-month-old and 1-day-old birds, remained cartilaginous. The fused nature of this part of the hyobranchial apparatus was obvious even in the 1-day-old birds examined. For convention and ease of comparison, the corpus and its rostral projection is referred to as the basihyale ( $O$ s basibranchiale rostrale), the caudal projection as the urohyale ( $O s$ basibranchiale caudale) and which together formed the basiurohyale. The rostral projection of the basihyale (RPB) extended from the rostral aspect of the corpus in the form of a dorso- 
ventrally flattened rectangle deeply embedded within the tongue parenchyma (Fig. 6). The rostral tip of the RPB displayed two bulbous projections separated by a shallow concavity (outlined in Fig. 3) and reached and shaped the apex of the tongue body. The dorsal surface of the tip of the RPB was connected via a band of connective tissue [unified portion of the basiarytaenoideus tendon (Bonga Tomlinson 2000)] to the ventral surface of the rostral process of the cricoid cartilage (Figs 3, 4B and 6). The ventral aspect of the tip of the RPB was related to the rostral aspect of the paraglossals as described above (Figs 3 and 4). The lateral, concave borders of the corpus of the basihyale (facets) formed the site of articulation for the proximal aspect of the rami of the ceratobranchiale (see below) (Figs 2B, 3 and 4). The urohyale projected from the caudal aspect of the corpus of the basihyale (Figs 2, 3, 4A and 6). It was wide at its point of origin from the corpus but narrowed progressively to end in a sharp point in the region of the sixth tracheal ring (Figs 2, 3 and 4A). The wider rostral part of the urohyale was loosely attached along its dorsal surface to the ventral surface of the body of the cricoid cartilage by fascia, whereas the tapered distal part was similarly attached to the proximal trachea (Fig. 6).

The most proximal part of the paired hyobranchial horns was the ceratobranchiale (Figs 1-5). This was the longest component of the hyobranchial apparatus, measuring approximately $71 \mathrm{~mm}(n=9)$ in subadult birds. The ceratobranchiale was ossified in all the age groups studied and consisted of a cylindrical shaft with bulbous proximal and distal extremities (Figs 2-5). The latter fitted snugly within the concave articular facets of the basihyale corpus and proximal end of the epibranchiale, respectively (Figs 2-5). The distal part of the horns was represented by the epibranchiale (Figs 1, 2A and 3). This was the second longest component of the hyobranchial apparatus, measuring approximately $42 \mathrm{~mm}(n=9)$ in subadult birds and was visibly curved (Figs 1 and 2). It was a cartilaginous, cylindrical structure of similar diameter proximally to that of the bulbous termination of the ceratobranchiale, but tapered distally to form a small, sometimes gently curved, point (Figs 1, $2 \mathrm{~A}$ and 3). There was no difference in length between the left and right ceratobranchiale or epibranchiale. The horns were enveloped by a thick, well-organised, mobile sheath of connective tissue, the Fascia vaginalis (Figs 1 and 2A).

\section{Topography of the hyobranchial apparatus}

The hyobranchial apparatus was attached rostrally to the parenchyma of the tongue via the cartilaginous rostral projection and part of the body of the basihyale which lay dorsal to the frenulum (Fig. 6). The rostral process of the cricoid cartilage of the larynx was also observed to support the root of the tongue (Fig. 6). The remaining elements of the central components of the hyobranchial apparatus (body of the basihyale and the urohyale) firmly anchored the tongue to the larynx (via the body of the cricoid cartilage) and proximal trachea (via the first six tracheal rings) (Figs 2, 4A and 6). The ossified ceratobranchiale extended caudo-laterally from the body of the basihyale and continued caudally over the cricoid cartilage of the larynx and the lateral musculature of the neck, a short distance beneath, but medial to, the ramus of the mandible (Figs 1 and 2). In the vicinity of the Pars caudalis of the ramus of the mandible, the ceratobranchiale articulated with the cartilaginous epibranchiale which curved sharply caudo-ventrally to attach to the caudo-lateral cervical musculature (Figs 1 and 2A). From its point of origin on the body of the basihyale, the horns of the hyobranchial apparatus (ceratobranchiale and epibranchiale) were firmly attached to all underlying structures by a double-layered sheath of fascia, the Fascia vaginalis (Figs 1 and 2A). 


\section{Laryngeal cartilages (Cartilagines larynges)}

The laryngeal skeleton of the ostrich was composed of cricoid, procricoid and paired arytenoid cartilages (Figs 3-6). The cricoid cartilage, which formed the bulk of the skeleton, was ring-shaped and consisted of the body (corpus) ventrally (Figs 2-4) and from which emanated the wings (alae) that extended caudo-laterally and dorsally to complete the ring (Figs 4B and 5). The wings articulated with one another along the midline and also with the caudo-lateral aspect of the procricoid (Figs 4B and 5). In semi-adult birds, the body displayed a central, plate-like, ossified region from which extended a blunt-ending, ossified, rostral projection (Figs 3, 4 and 6). This projection was loosely attached along its ventral surface to the dorsal aspect of the body of the basihyale by a layer of connective tissue (Fig. 6). The tip of the projection was connected to the tip of the rostral projection of the basihyale by a strong band of fibrous connective tissue (Figs 3, 4B and 6). As noted earlier, this band of tissue was firmly attached to the ventral surface of the tip of the cricoid projection and to the dorsal aspect of the tip of the projection of the basihyale (Figs 3, 4B and 6). For most of its length, the band was loosely attached to the dorsal surface of the projection of the basihyale (Fig. 6). In younger birds, the body of the cricoid cartilage remained cartilaginous. The caudal margin of the cricoid cartilage was attached by mucous membrane to the proximal cartilage rings of the trachea. The point of contact between the two structures was inclined in a ventro-rostral direction.

The small, centrally positioned procricoid cartilage was situated just caudal to the caudal extremity of the glottis and effectively linked the caudal aspect of the paired arytenoids with the tips of the wings of the cricoid cartilage (Fig. 5). The procricoid was oriented at almost 90 degrees to the other elements of the laryngeal skeleton and formed a single, shield-shaped structure which articulated with the caudo-medial aspect of the paired arytenoids and with the rostro-medial aspect of the wings of the cricoid (Fig. 5). The articulation of the procricoid with the wings of the cricoid and the articulation of the wings with each other created a Yshaped point of contact between the two cartilages (Fig. 5).

The two arytenoid cartilages lay dorsally and formed the margins of the glottis (Figs 4B and 6). Each of the arytenoids was dorso-ventrally flattened with a straight medial border on which the lips of the glottis were accommodated (Figs 4B, 5 and 6). Despite the relatively high profile of the lips, they were not supported internally by extensions from the medial border of the arytenoids. The lateral borders had a scalloped appearance due to the presence of two large lateral projections and a smaller caudo-medial projection which articulated with (or abutted) the procricoid (see above) (Figs 3 and 4B). The larger rostro-lateral projections were caudo-laterally directed, hook-like structures, whereas the smaller, more caudally positioned projections were blunt and caudally directed (Figs 3 and 4B). These projections formed the support of the mucosal elaborations seen externally on the laryngeal mound.

The positioning of the arytenoid cartilages relative to the wings of the cricoid cartilage resulted in the formation of two large, cat's-eye-shaped gaps between them (Figs 4B and 5). These were covered by the mucous membrane and supporting connective tissue lining the laryngeal cavity and which was attached to the ventral surface of the arytenoids. 


\section{Discussion}

\section{Hyobranchial apparatus}

The results of this study broadly confirmed previous findings (Webb 1957; Bezuidenhout 1999; Bonga Tomlinson 2000) that the hyobranchial apparatus of the ostrich consists of both central and paired caudo-lateral elements. In agreement with Webb (1957) and Bonga Tomlinson (2000), the paired caudo-lateral components (horns or cornu) of the apparatus consisted of the ceratobranchiale (which articulated with the body of the basihyale) and the epibranchiale (which articulated with the ceratobranchiale), both components being rod-like structures which appeared circular in cross section. Bezuidenhout (1999) provided no structural detail of the cornu, noting simply that they consisted of paired ceratobranchial and cartilaginous parts, the latter presumably representing the epibranchiale described in the present study and by Webb (1957).

In defining the central component, Bezuidenhout (1999) briefly mentioned that it consisted of the entoglossum (paraglossum), basibranchiale rostrale and basibranchiale caudale, again without providing any structural detail. In the cassowary (Parker 1866), emu (Parker 1866; Bonga Tomlinson 2000; Crole and Soley 2009a, 2012b), kiwi (Apteryx australis) (Parker 1891) and greater rhea (Parker 1866; Bonga Tomlinson 2000; Crole and Soley 2012a), the paraglossum is a single structure and is related dorsally to the rostral projection of the basihyale. However, in the ostrich, the paraglossum consists of twin components termed the paraglossalia, situated ventro-lateral to the rostral projection of the basihyale (Bonga Tomlinson 2000; Crole and Soley 2012b; present study) and which support the ventro-lateral aspect of the tongue. The present study further revealed that the paraglossalia were connected rostrally to each other by fibrous connective tissue. The presence of paraglossalia is unique amongst the ratites to the ostrich (Bonga Tomlinson 2000; Crole and Soley 2009a); however, the paraglossum in the greater rhea, although a single structure, displays a rostral, central oval defect which is open-ended in chicks and closes in the subadult (Crole and Soley 2012a) and most closely resembles the two separate paraglossalia of the ostrich. It would appear that the unusual position and shape of the paraglossalia in Struthio, in comparison with other ratites (see Crole and Soley 2009a), have led to them being overlooked (Warren 1725; Meckel 1829; Porcescu 2007; Tadjalli et al. 2008) or being mistakenly identified. In the latter instance, the most frequent error has been the misidentification of the rostral extremity of the rostral projection of the basihyale as the paraglossal cartilage (Parker 1866; Faraggiana 1933; Webb 1957; Jackowiak and Ludwig 2008; Guimarães et al. 2009; Poost Pasand et al. 2010b, 2011). This confusion easily arises as the rostral projection of the basihyale is flat, broad, runs to the apex of the tongue and has two rounded, lateral projections. Furthermore, it is cartilaginous and in a median, longitudinal section of the tongue is located in the position where the paraglossum would be situated in other ratite species. The paraglossalia in the ostrich have been noted by Guimarães et al. (2009) but only accurately depicted and described by Bonga Tomlinson (2000), Crole and Soley (2012b) and now confirmed in the present study. Paired paraglossals have also been described in Psittaciformes (Mivart 1895; Beddard 1898; Homberger 1986), the separate elements being bound rostrally by a cartilaginous or bony isthmus (Mivart 1895; Beddard 1898), and some reports on the domestic fowl describe the Os entoglossum as being double (Nickel et al. 1977). Unlike in the domestic fowl and duck where the paraglossum consists of bony (caudal) and cartilaginous (rostral) parts (Ellenberger and Baum 1943; McLelland 1975; Homberger and Meyers 1989), the paraglossalia in the ostrich are cartilaginous, even in 12to 14-month-old birds. As noted by Crole and Soley (2012b), the paraglossals play an integral 
role in the functioning of the linguo-laryngeal apparatus by virtue of their unique shape which both facilitates this mechanism and provides support for the tongue.

In the ostrich, the remaining central component of the hyobranchial apparatus comprised a single fused structure, the basiurohyale, representing the basihyale and urohyale described in other birds (Baumel and Witmer 1993). It was noted by Bonga Tomlinson (2000) that all palaeognathous taxa (except the rhea which has no urohyale) display one continuous, cartilaginous structure (basiurohyale) formed by the basihyale and urohyale. Webb (1957) also described a fused structure composed of a dorso-ventrally flattened median basal plate and which anteriorly formed the 'Os entoglossum' and posteriorly the tapered urohyale. Webb (1957) further notes that the median basal plate (fused basihyale and urohyale) 'is in no way subdivided either by ossification or by being laid down as separate areas of chondrification', even in 27- and 30-day-old embryos. The fused nature of the basihyale and urohyale in the ostrich, even during embryonal stages, contrasts sharply with the situation in other avian species where the two components are separate in young birds, although fused to one another in adults (Baumel and Witmer 1993). Despite being fused, the central component of the hyobranchial apparatus in the ostrich consists essentially of three parts, namely a central body (corpus or basihyoideum) with which the paired ceratobranchiale articulate laterally, and rostral and caudal projections representing the lingual process and urohyale, respectively. As with the paraglossalia, the basihyale (body and rostral projection) is uniquely shaped in the ostrich in comparison with that in other extant ratites (Crole and Soley 2012a). In contrast to the cylindrical, rostrally tapering, pointed rostral projection of the basihyale in the emu (Crole and Soley 2009a), greater rhea (Crole and Soley 2012a), cassowary (Parker 1866) and kiwi (Parker 1891), that of the ostrich is broad, dorso-ventrally flattened, reaches the apex of the tongue and the body is mineralised/ossified in older birds. The basihyale has recently been closely linked, by virtue of its shape and connection to the paraglossal/paraglossalia, in the advanced functioning and more complex movements of the ratite tongue reported in the greater rhea (Crole and Soley 2012a), emu (Crole and Soley 2009a) and ostrich (Crole and Soley 2012b). It would appear that the flattened, spatulate shape of the basihyale allows a greater attachment area for the $M$. cricohyoideus reported by Bonga Tomlinson (2000) which is unique to the ostrich amongst palaeognaths, in that it is partly situated within the tongue body (Bonga Tomlinson 2000). This muscle is integral to the functioning of the linguo-laryngeal apparatus in the ostrich by decreasing the distance between the tongue and the larynx (Crole and Soley 2012b).

As noted by Bonga Tomlinson (2000), the urohyale restricts ventro-flexion of the tongue body by limiting tongue extension rostral to the basihyale. As the urohyale is absent in the greater rhea (Bonga Tomlinson 2000; Crole and Soley 2012a) and comparatively the longest in the ostrich (Bonga Tomlinson 2000; present study), the tongue of the ostrich would be the least flexible amongst the ratites (Bonga Tomlinson 2000). Interpreted in respect of the functioning of the linguo-laryngeal apparatus in the ostrich (Crole and Soley 2012b), ventroflexion of the tongue would inhibit the partial envelopment of the laryngeal mound by the lingual pocket during swallowing, hence the stabilisation and support of the tongue body by the long urohyale as well as the rostral projection of the cricoid cartilage.

Webb (1957) states that in both ostrich embryos and adult birds, the only ossified component of the hyobranchial apparatus is the ceratobranchiale, while all the other parts remain cartilaginous. Bonga Tomlinson (2000) also notes that the paraglossal, basihyale and urohyale of palaeognaths do not ossify in contrast to the situation in neognaths. However, the results of the present study demonstrated that in most of the 12- to 14-month-old birds from 
this study, the body of the fused basihyale and urohyale was clearly ossified in addition to the ossification of the paired ceratobranchiale. As the oldest birds studied in the present work were 12 to 14 months old, it is impossible to speculate on whether additional parts of the ostrich hyobranchial apparatus become ossified over time as is the case in the domestic fowl where parts of the paraglossum, urohyale and epibranchiale are ossified in addition to the paired ceratobranchiale (Homberger and Meyers 1989). It has also been reported that the caudal portion of the basihyale displays signs of ossification in the emu (Crole and Soley 2009b). These observations regarding ossification of the basihyale in the emu (Crole and Soley 2009b) and ostrich (present study) challenge the assertion that these structures never ossify in palaeognathous birds (Bonga Tomlinson 2000).

\section{Topography of the hyobranchial apparatus}

Bezuidenhout (1999) reported that the horns of the hyobranchial apparatus in the ostrich 'suspend the apparatus from the ventral surface of the cranium', while Webb (1957) noted that the cartilaginous epibranchiale 'extends to the posterior end of the skull'. In the various age groups of birds examined in the present study, it was observed that the paired cornu, while indeed suspending the hyobranchial apparatus, at no point passed close to the skull, but in fact curved downwards (caudo-ventrally) away from the skull, as described and depicted by Bonga Tomlinson (2000). This contrasts with the situation in the domestic fowl where the horns of the hyobranchial apparatus curve upwards to attach to the occipital region of the skull (Homberger and Meyers 1989). In both the ostrich and fowl (Homberger and Meyers 1989), the attachment of the ceratobranchiale and epibranchiale to the underlying structures was effected by a sheath-like fascia, the Fascia vaginalis.

\section{Laryngeal cartilages}

Confusion exists in the literature regarding the identification and number of cartilages forming the larynx in ratites. Fowler (1991) describes arytenoids, cricoid and thyroid cartilages in ratites, Bezuidenhout (1999) describes two cricoid and two arytenoid cartilages in the ostrich, and Tadjalli et al. (2008) mention an unpaired cricoid cartilage and paired arytenoid cartilages in the same species. In accordance with the information on birds in general (McLelland 1989), as well as in other ratite species such as the emu (McLelland 1989; Crole and Soley 2010) and greater rhea (Crole and Soley 2012a), this study demonstrated that the larynx of the ostrich consisted of cricoid, procricoid and two arytenoid cartilages and confirmed the absence of thyroid and epiglottic cartilages (Nickel et al. 1977; King and McLelland 1984).

The large cricoid cartilage was composed of a body and two wings that articulated caudomedially with each other. A similar arrangement, based on the work of S.S. White, is illustrated for the emu and the ostrich (McLelland 1989) and the greater rhea (Crole and Soley 2012a). The incorporation of one or more tracheal rings into the cricoid has been recognised in numerous bird species (Boccius 1858) including Columba (Zweers et al. 1981) and the greater rhea (Crole and Soley 2012a); however, this phenomenon was not observed in the ostrich. The elongated rostral projection of the cricoid cartilage is unique to the ostrich amongst ratite species studied. The defined tract of connective tissue connecting this projection with the rostral projection of the basihyale most likely represents the unified tendon of the paired basiarytenoideus tendons reported by Bonga Tomlinson (2000) in the ostrich. The basiarytenoideus muscle is unique to palaeognaths (Bonga Tomlinson 2000) and most likely assists with the functioning of the linguo-laryngeal apparatus reported in the 
ostrich and emu (Crole and Soley 2012b). In the emu and greater rhea, the basiarytenoid tendons insert onto a basihyale connective tissue sheath (Bonga Tomlinson 2000; Crole and Soley 2012a) which surrounds the round rostral projection of the basihyale. The flattened unified tendon in the ostrich is most likely an adaptation to the flattened basiurohyale present in this species. The small procricoid cartilage of the ostrich was rhomboidal in outline and articulated with both the wings of the cricoid cartilage and the caudo-medial aspect of the paired arytenoid cartilages as reported in other birds (McLelland 1989). In the chicken, the procricoid articulates with the medial border of each cricoid wing (White 1975). In the ostrich, it articulates with the rostro-medial border of each cricoid wing similar to that noted in the greater rhea (Crole and Soley 2012a) and the crow (Bock 1978). However, the procricoid appears to articulate with only the rostral border of the cricoid wings in the emu (McLelland 1989 - sketch by S.S. White).

The paired arytenoid cartilages were flat and showed no elaborations except for the presence of two large lateral and two smaller caudal projections which distinguish these cartilages from those of the emu (McLelland 1989 - sketch by S.S. White) and greater rhea (Crole and Soley 2012a). The two rostral lateral projections provide the supporting structure over which the caudal lingual papillae of the ostrich tongue hook when the tongue pocket encloses the glottis during retraction (Crole and Soley 2012b). The rostral and caudal processes typical of other avian species such as the domestic fowl (White 1975; McLelland 1989) were not observed in the ostrich, the arytenoid cartilages in this species appearing to consist only of a body (corpus). Ossification of the laryngeal cartilages in the domestic fowl is reported to occur in the body and wings of the cricoid and the body of the procricoid and arytenoid cartilages (Hogg 1982), whereas in the pigeon, the wings of the cricoid and tail of the procricoid remain cartilaginous while the body of the arytenoids is only partially ossified (Zweers et al. 1981). The tip of the cricoid is reportedly cartilaginous in the domestic fowl (White 1975; McLelland 1989) and crows (Zweers and Berkhoudt 1987). Ossification of the rostral margin of the wings of the cricoid was reported in an 8-month-old greater rhea (Crole and Soley 2012a). In the 12- to 14-month-old ostriches studied, only part of the body and the rostral process of the cricoid cartilage were ossified. Tadjalli et al. (2008) also noted ossification of the body of the cricoid in the ostrich. This supports the observation that in birds, the 'cricoid cartilage tends to early ossification' (Nickel et al. 1977). Whether ossification eventually occurs with age in other parts of the laryngeal skeleton of the ostrich remains unknown. The ossification of that part of the cricoid cartilage overlying the body of the basihyale (which also ossifies) may be indicative of the strengthening of these structures required to support the functioning of the linguo-laryngeal apparatus (Crole and Soley 2012b).

It is concluded that, although the ostrich larynx displays the typical combination of cartilages described for birds in general, it differs markedly in respect of the relatively simple design of the paired arytenoid cartilages. This feature, together with structural modifications of elements of the hyobranchial apparatus, would appear to represent specific adaptations aimed at facilitating the functioning of the linguo-laryngeal apparatus reported in this species (Crole and Soley 2012b).

\section{Acknowledgements}

We thank the management and staff at the Oryx Ostrich Abattoir (Krugersdorp, Gauteng, South Africa) for providing the ostrich heads, and the support staff of the Department of 
Anatomy and Physiology, Faculty of Veterinary Science, University of Pretoria for their assistance. This work was funded by the University of Pretoria.

\section{References}

Baumel, J. J. and Witmer, L. M. 1993. Osteologia. In: Baumel, J. J., King, A. S., Breazile, J. E., Evans, H. E. and Vanden Berge, J. C. (Eds): Handbook of Avian Anatomy: Nomina Anatomica Avium, 2nd edn, pp. 45-132. Nuttall Ornithological Club, Cambridge, MA.

Baumel, J. J., King, A. S., Breazile, J. E., Evans, H. E. and Vanden Berge, J. C. 1993. Handbook of Avian Anatomy: Nomina Anatomica Avium, 2nd edn, 779 p. Nuttall Ornithological Club, Cambridge, MA.

Beddard, F. E. 1898. The Structure and Classification of Birds, 612 p. Longmans, Green and Co., London.

Bezuidenhout, A. J. 1999. Anatomy. In: Deeming, D. C. (Ed.): The Ostrich, Biology, Production and Health, pp. 13-49. CABI Publishing, Wallingford, UK.

Boccius, W. 1858. Ueber den oberen Kehlköpf der vögel. Archiv für Anatomie und Physiologie und Wissenschaftliche Medicin 1858: 614-649.

Bock, W. J. 1978. Morphology of the larynx of Corvus brachyrhynchos (Passeriformes: Corvidae). Wilson Bulletin 90: 553-565.

Bonga Tomlinson, C. A. 2000. Feeding in paleognathous birds. In: Schwenk, K. (Ed.): Feeding: Form, Function, and Evolution in Tetrapod Vertebrates, pp. 359-394. Academic Press, San Diego, CA.

Crole, M. R. and Soley, J. T. 2009a. Morphology of the tongue of the emu (Dromaius novaehollandiae). I. Gross anatomical features and topography. Onderstepoort Journal of Veterinary Research 76: 335-345.

Crole, M. R. and Soley, J. T. 2009b. Morphology of the tongue of the emu (Dromaius novaehollandiae). II. Histological features. Onderstepoort Journal of Veterinary Research 76: 347-361.

Crole, M. R. and Soley, J. T. 2010. Gross morphology of the intra-oral rhamphotheca, oropharynx and proximal esophagus of the emu (Dromaius novaehollandiae). Anatomia Histologia Embryologia 39: 207-218.

Crole, M. R. and Soley, J. T. 2012a. Gross anatomical features of the tongue, lingual skeleton and laryngeal mound of Rhea americana (Palaeognatha, Aves): Morpho-functional considerations. Zoomorphology 131: 265-273.

Crole, M. R. and Soley, J. T. 2012b. What prevents Struthio camelus and Dromaius novaehollandiae (Palaeognathae) from choking? A novel anatomical mechanism in ratites, the linguo-laryngeal apparatus. Frontiers in Zoology 9: 11. 
Duerden, J. E. 1912. Experiments with ostriches XVIII. The anatomy and physiology of the ostrich. A. The external characters. Journal of the Department of Agriculture, Union of South Africa 3: 22-29.

Ellenberger, W. and Baum, H. 1943. Handbuch der Vergleichenden Anatomie der Haustiere, 18th edn, 1155 p. Springer-Verlag, Berlin.

Faraggiana, R. 1933. Sulla morfologia della lingua e del rialzo laringeo di alcune specie di Uccelli Ratiti e Carenati non comuni. Bolletino dei Musei di Zoologia Anatomia Comparata 43: 313-323.

Feder, F.-H. 1972. Zur mikroskopischen Anatomie des Verdauungsapparates beim Nandu (Rhea americana). Anatomischer Anzeiger 132: 250-265.

Fowler, M. E. 1991. Comparative clinical anatomy of ratites. Journal of Zoo and Wildlife Medicine 22: 204-227.

Guimarães, J. P., Mari, R. B., de Carvalho, H. S. and Watanabe, I. 2009. Fine structure of the dorsal surface of ostrich's (Struthio camelus) tongue. Zoological Science 26: 153-156.

Hogg, D. A. 1982. Ossification of the laryngeal, tracheal and syringeal cartilages in the domestic fowl. Journal of Anatomy 134: 57-71.

Homberger, D. G. 1986. The Lingual Apparatus of the African Grey Parrot, Psittacus erithacus L. (Aves:Psittacidae): Description and Theoretical Mechanical Analysis, 233 p. Ornithological Monographs no 39, American Ornithologists' Union, Washington, DC.

Homberger, D. G. and Meyers, R. A. 1989. Morphology of the lingual apparatus of the domestic chicken, Gallus gallus, with special attention to the structure of the fasciae. American Journal of Anatomy 186: 217-257.

Direct Link:

Jackowiak, H. and Ludwig, M. 2008. Light and scanning electron microscopic study of the structure of the ostrich (Strutio camelus) tongue. Zoological Science 25: 188-194.

King, A. S. and McLelland, J. 1984. Birds - Their Structure and Function, 2nd edn, 334 p. Baillière Tindall, London.

McLelland, J. 1975. Aves digestive system. In: Rosenbaum, C. E., Ghoshal, N. G. and Hillmann, D. (Eds): Sisson and Grossman's The Anatomy of the Domestic Animals, vol. 2, pp. 1857-1882. W.B. Saunders Company, Philadelphia, PA.

McLelland, J. 1989. Larynx and trachea. In: King, A. S. and McLelland, J. (Eds): Form and Function in Birds, vol. 4, pp. 69-103. Academic Press, London.

Meckel, J. F. 1829. System der vergleichenden Anatomie, 688 p. Der Rehgerschen Buchhanlung, Halle.

Mivart, St. G. 1895. On the hyoid bone of certain parrots. Proceedings of the Zoological Society of London 19: 162-174. 
Nickel, R., Schummer, A. and Seiferle, E. 1977. Anatomy of the Domestic Birds, 202 p. Verlag Paul Parey, Berlin.

Owen, R. 1879. Memoirs on the Extinct and Wingless Birds of New Zealand; with an Appendix of those of England, Australia, Newfoundland, Mauritius and Rodriguez, vol. 1, 81 p. John van Voorst, London.

Parker, W. K. 1866. On the structure and development of the skull in the ostrich tribe. Philosophical Transactions of the Royal Society of London, B 156: 113-183.

Parker, T. J. 1891. Observations on the anatomy and development of apteryx. Philosophical Transactions of the Royal Society of London, B 182: 25-134.

Poost Pasand, A., Tadjalli, M. and Mansouri, H. 2010a. Macroscopic and microscopic study of larynx in male ostrich. Global Veterinaria 5: 109-115.

Poost Pasand, A., Tadjalli, M. and Mansouri, H. 2010b. Microscopic study on the tongue of male ostrich. European Journal of Biological Sciences 2: 24-31.

Poost Pasand, A., Tadjalli, M. and Parto, P. 2011. Gross anatomy of the tongue in male ostrich. World Journal of Zoology 6: 346-349.

Porcescu, G. 2007. Comparative morphology of the digestive tract of the black African ostrich, hen and turkey, PhD thesis. Agrarian State University of Moldova, Moldova. Available from: http://www.cnaa.acad.md/en/thesis/6828/.

Tadjalli, M., Mansouri, S. H. and Poostpasand, A. 2008. Gross anatomy of the oropharyngeal cavity in the ostrich (Struthio camelus). Iranian Journal of Veterinary Research 9: 316-323.

Warren, G. 1725. Observations upon the Dissection of an Ostrich, Communicated in a Letter to the Publisher, by the Ingenious Mr. George Warren, Surgeon in Cambridge. Philosophical Transactions 34: 113-117.

Webb, M. 1957. The ontogeny of the cranial bones, cranial peripheral and cranial parasympathetic nerves, together with a study of the visceral muscles of Struthio. Acta Zoologica-Stockholm 38: 81-202.

Direct Link:

White, S. S. 1975. The larynx. In: Getty, R. (Ed.): Sisson and Grossman's The Anatomy of the Domestic Animals, vol. 2, pp. 1891-1897. W.B. Saunders, Philadelphia, PA.

Zweers, G. A. and Berkhoudt, H. 1987. Larynx and pharynx of crows (Corvus corone L. and C. monedula L., Paseriformes: Corvidae). Netherlands Journal of Zoology 37: 365-393.

Zweers, G. A., Van Pelt, H. C. and Beckers, A. 1981. Morphology and mechanics of the larynx of the pigeon (Columba livia L.): A drill-chuck system (Aves). Zoomorphology 99: $37-69$. 